\title{
Off-Pump CABG for Mulitvessel Coronary Artery Disease-Safe Incorporation into Surgical Practice
}

\author{
Catharina Nesselmann ${ }^{1}$, Sadia Aftab $^{2}$, Manikandan Chandran ${ }^{3}$, Fraser W. H. Sutherland ${ }^{2}$ \\ ${ }^{1}$ Department of Cardiac Surgery, University of Rostock, Rostock, Germany; ${ }^{2}$ Department for Cardiothoracic Surgery, Golden Jubilee \\ National Hospital, Glasgow, Scotland; ${ }^{3}$ Anaesthetic Department, Royal Hospital for Sick Children, Glasgow, Scotland. \\ Email: catharina.nesselmann@med.uni-rostock.de
}

Received May $20^{\text {th }}, 2012$; revised June $18^{\text {th }}, 2012$; accepted June $25^{\text {th }}, 2012$

\begin{abstract}
Introduction: Since its revival two decades ago development of the surgical technique, along with evidence and clinical outcomes of off-pump coronary artery bypass surgery (OPCAB) were brought into focus. Methods: We report a single surgeon, single center experience of the first 37 consecutive patients undergoing off-pump surgery. Patients were selected for OPCAB (study group) individually and matched retrospectively to a control group of 113 patients performed over an identical time frame. Data were retrieved from a hospital data base (TOMCAT). Results: Mean Logistic European System of Cardiac Operative Risk Stratification (EuroSCORE) was slightly higher in the off-pump group (3.8\% versus $2.9 \%$ ). One patient died during the study and this was in the off-pump CAB group (OPCAB-30 day mortality 2.7\%). Operating time was slightly shorter in the off-pump group ( 3 hours 28 minutes versus 3 hours 49 minutes, $p=0.15$ ). After exclusion of outliers, total hospital stay was significantly shorter for off-pump cases (mean 6.8 days versus 8.37 days), while Intensive Care Unit (ICU) stay (1.2 versus 1.4 days) and ventilation time were only slightly shorter ( 9.35 hours versus 10.6 hours) for off-pump cases. Chest tube drainage was significantly lower in the off-pump group (484 ml versus $744 \mathrm{ml}, p=0.04$ ) with correspondingly slightly lower transfusion requirements and significantly increased discharge haemoglobin concentrations in OPCAB. There was one cerebrovascular accident (CVA) in the off-pump group and none in the on-pump group. Conclusion: In this study we show short term outcomes for introduction of off-pump into surgical technique. Length of ICU stay, ventilation times, chest tube drainage, transfusion requirements and pre-discharge haemoglobin concentration all appeared superior in the off pump group. The off-pump technique was safely introduced into the surgeon's service with relatively little mortality. Experience of surgeon was considered advantageous for fast adaption of the technique. However, numbers were too small to make strong inferences. With practice more patients should benefit from the technique.
\end{abstract}

Keywords: Off-Pump versus On-Pump; Coronary Artery Bypass Grafting; Without Cardiopulmonary Bypass; Cardiac Surgery

\section{Introduction}

Coronary artery disease, the manifestation of atherosclerosis in coronary arteries, is a leading cause of death and morbidity throughout the world. A growing number of patients show need for surgical therapy. Ever since introduction of coronary artery bypass grafting (CABG) advancements were attempted to circumvent detrimental effects of the surgical procedure itself without impairment of surgical vascularization result. These side effects were often were assigned to application of extracorporeal circulation (ECC). Avoiding ECC might mean less detrimental effects related to systemic inflammatory response syndrome and endorgan dysfunction, such as coagulation, renal impairment, lung injury, stroke, delirium and more subtle neurocognitive changes [1,2]. A lot of refinements have been made in anaesthetic and surgical techniques, such as designs of pumps, oxygenators and cannulae, and advantage from avoiding ECC, reduced morbidity was not impressively apparent throughout the studies. Overall proportion of isolated off-pump CABG is currently $20.2 \%$ for the European countries [3] and about $25 \%$ in the US [4]. In Asian countries majority of CABG surgery is performed off-pump. There are European institutions that report particularly high percentages of off-pump CABG with dedicated training programs for surgical trainees [5,6]. Applying CABG may reduce costs, one of the reasons it lead to application in South Africa and revival of the technique in early 1990 s. With low intraoperative conversion rate $(\leq 8.5 \%)$ costs can be reduced [7]. Currently there is no guideline suggesting off-pump as technique of first choice in any 
anatomic constellation, risk status or surgeons capability in coronary artery bypass surgery. As a result of a large meta-analysis [8] and recent NICE guidance CABG without cardiopulmonary bypass $(\mathrm{CPB})$ can be performed equally safe to on-pump $\mathrm{CABG}$ with regard to mortality. Subgroups even benefiting from OPCAB were high-risk patients and patients with specific risk factors, such as EuroSCORE > 5, LV dysfunction, and atheromatous aorta: Class IIa, Level B (weight of evidence in favor of usefulness or efficiency, data derived from a single randomized or nonrandomized studies) [8] and groups over 70 years age to achieve a lower incidence of cerebral injury, and in high-risk groups, particularly patients with renal impairment to achieve less need for postoperative renal support [2]. In low risk patients cognitive outcome after 5 years did not differ between on-pump and off-pump CABG (281 patients, randomized controlled trial) [9].

It is apparent that sufficient construction of distal anastomoses on beating heart can be technically challenging, giving rise to concerns that graft patency and completeness of revascularization may be altered using off-pump CABG. These concerns were partly confirmed $[10,11]$, but literature is inconsistent $[12,13]$. Recently not only graft patency but effectiveness of revascularization, estimated from detailed angiographies and Fitz Gibbon's patency classification, were suggested as relevant outcome parameter [10].

On the other hand special care should be taken to assure that expertise of performing surgeons and attending supervisors at time of initiation of OPCAB and regarding studies are provided as adoption to OPCAB can be difficult for surgeons or residents not trained in the technique. This was being emphasized repeatedly [4,14]. Still, proper training may not have been the case in all randomized controlled trials (RCTs) conducted and therefore we hypothesize that surgeon's expertise and careful training can make OPCAB surgery a beneficial technique concerning short-term outcomes and can contribute to safe introduction of the technique into a surgeons service.

We aim to present our clinical experience with offpump CABG performed by a single surgeon in a single center, with solely this surgeon performing the technique at this institution, and to compare the results with onpump CABG performed by the same surgeon over the same time frame.

\section{Methods}

\subsection{Training Model}

A business case was submitted to the hospital management for development of this service. Policies by National Health Service Trust and National Institute for Clinical Excellence (NICE) were appreciated. According to NICE guidance for off-pump CABG the use of offpump approach in coronary surgery is as safe as on-pump CABG [2]. The consultant surgeon undertook focused learning of the off-pump technique through reading of peer reviewed journals and product literature, study of multimedia resources, discussion with colleagues and participation in an intensive two day training course run by two experienced off-pump surgeons, Mr. Brian Fabri and Mr. Mark Pullen, at the Liverpool Heart and Chest Hospital, Liverpool, United Kingdom. A further observation from outside surgeons (preceptoring and proctoring) in the process of introduction was not provided during the time of the study frame. Theatre team was introduced sufficiently in the new technique by the surgeon and manufacturer's agents.

\subsection{Patients}

From March 2008 to July 2009, the first 37 consecutive patients operated off-pump CAB (study group) were analysed and compared with a control group of patients underwent on-pump $\mathrm{CAB}$ during the same time frame. All operations were performed in the same institution of maximum cardiac and thoracic surgery care. Patients scheduled for coronary artery bypass graft surgery were selected into the study group according to the discretion of the surgeon. Factors evaluated were perceived level of difficulty, target sizes, hemodynamic stability, and tolerance to cardiac mobilization. Patients with re-operation were excluded from the study but operated beating heart on-pump.

\subsection{Surgical Procedure}

All patients were operated open-heart; the surgical approach was median sternotomy. The left internal thoracic artery was harvested in pedicled form and placed in a papaverinesoaked compress until use. The left pleura was widely opened. Radial artery was harvested in a skeletonised fashion and only used in a few cases (data not shown). Saphenous veins were openely harvested and stored in a heparin solution until use.

In the off-pump group exposure of target vessels was facilitated using the Trendelenburg position, with swabs in the transverse sinus, and one or two deep pericardial traction sutures. Right pleura was opened for hemodynamic stability. For stabilizing the heart Medtronic Octopus version 4.3 or Maquet ACROBAT vacuum stabilizer system were used both according to availability. Distal anastomoses were constructed with 7-0 polypropylene and proximal anastomoses onto the aorta with 6-0 polypropylene. Sequence of grafting consisted of left anterior descending artery (LAD) grafted first, followed by the vessels of the left side of the heart and finally vessels of the inferior wall. For construction of distal an- 
stomoses intracoronary shunts $\left(\right.$ ClearView $^{\circledR}$ Medtronic Inc. Minneapolis, USA) were used in all cases. Visualisation was further optimized applying a blower device (ClearView ${ }^{\circledR}$ Medtronic Inc, Minneapolis, USA). In the control group the aorta ascendens and the right atrium (using a two-stage cannula) were cannulated, and pulmonary artery was vented. Cold blood cardioplegia was delivered into the aortic root to provide for myocardial protection. After completion of the distal anastomoses, hereby using intracoronary shunts in selected anatomical targets, the aortic clamp was removed and the proximal anastomoses were performed with partial tangential clamping.

Anaesthetic procedure differed between cases due to the range of techniques practiced by anaesthetists within the institution. Anticoagulation was achieved using (155 $\mathrm{IU} / \mathrm{kg}$ ) Heparin. The activated clotting time was maintained above $300 \mathrm{sec}$ in off-pump and above $400 \mathrm{sec}$ in on-pump cases. Lower ACT for off-pump cases was due to less expected complement cascade activation from no CPB and inherent surface-blood interaction. Heparin was reversed with (equivalent units of) protamine sulphate at the end of the procedure. A cell saver system was used for all patients. Mean arterial pressure was kept between 50 and $70 \mathrm{mmHg}$ by maintaining optimal preload, repositioning of the heart and the use of vasoconstrictors (metaraminol, noradrenaline). Body temperatures were kept up using warming blankets, room temperature regulation, warm intravenous infusions, and a sterile warming mattress. All patients received Aspirin in an initial dose of $300 \mathrm{mg}$ per rectum after 6 hours - if not contraindicated - and a daily oral dose of $75 \mathrm{mg}$ from the first postoperative day.

Postoperative care was supervised by the surgeon. All patients were kept in intensive care unit postoperatively until next day. Transfer from itu to high dependency unit was decided during morning round the day after surgery. The transfer from high dependency unit (HDU) to ward took place the second postoperative day earliest.

\subsection{Statistical Analysis}

Clinical data was obtained from the internal cardiovascular database, Philips CVIS, version Microsoft SQL 200 op0. Statistical analysis was performed using Microsoft Excel (Version 2003). For continuous data the variables were expressed as mean \pm standard deviation (SD), median with interquartile range (IQR) and analysed by the two sample student's t-test. Confidence intervals for the difference in two population means were given for duration of ventilation and length of stay. The trim mean function was also applied to continuous data to evaluate the mean once outliers were excluded. Categorical data was compared between groups using the chi-squared test and confidence intervals for the difference in two propor- tions were provided for postoperative complications where stated. Statistical significance was defined as $p$-value $<0.05$. Mortality was defined as all cause hospital mortality within 30 days after the surgical procedure.

\section{Results}

We analysed 150 patients of whom 37 were undergoing off-pump CABG (study group) and 113 conventional $\mathrm{CABG}$ (control group). The two groups were operated consecutively by the same surgeon during the same time period. Hence the surgeon's rate of OPCAB/overall CAB during study period was $24.67 \%$. The demographic and preoperative clinical characteristics of the two groups are presented in Table 1. Age distribution, gender, comorbidities, and New York Heart Association Class

Table 1. Demographic, preand intraoperative clinical characteristics of patients operated by single experienced surgeon.

\begin{tabular}{|c|c|c|c|}
\hline $\begin{array}{l}\text { Demographic, } \\
\text { Pre- and } \\
\text { Intraoperative } \\
\text { Characteristics }\end{array}$ & $\begin{array}{c}\text { Off Pump } \\
\text { Group } \\
\mathrm{n}=37(\%)\end{array}$ & $\begin{array}{l}\text { On Pump } \\
\text { Group } \\
\mathrm{n}=113(\%)\end{array}$ & $p$-Value \\
\hline \multicolumn{4}{|l|}{ Age } \\
\hline$<60 \mathrm{y}$ & $13(35.1)$ & $28(24.8)$ & 0.36 \\
\hline $60-74 y$ & $17(45.9)$ & $64(56.6)$ & 0.53 \\
\hline$\geq 75 y$ & $7(18.9)$ & $21(18.6)$ & 0.67 \\
\hline Female & $8(21.6)$ & $19(16.8)$ & 0.51 \\
\hline Diabetes & $13(35.1)$ & $32(28.3)$ & 0.43 \\
\hline Renal Failure & $2(5.4)$ & $1(0.9)$ & 0.09 \\
\hline Hypertension & $27(73.0)$ & $80(70.8)$ & 0.80 \\
\hline Claudication & $5(13.5)$ & $9(8.0)$ & 0.31 \\
\hline CVA & $2(5.4)$ & $13(11.5)$ & 0.28 \\
\hline COPD & $2(5.4)$ & $5(4.4)$ & 0.81 \\
\hline Previous & $0(0)$ & $1(0.9)$ & 0.57 \\
\hline \multicolumn{4}{|l|}{ CABG } \\
\hline $\mathrm{EF}<50 \%$ & $6(16.2)$ & $30(26.5)$ & 0.20 \\
\hline \multicolumn{4}{|l|}{ NYHA Class } \\
\hline I & $1(2.7)$ & $10(8.8)$ & 0.21 \\
\hline II & $21(56.8)$ & $56(49.6)$ & 0.45 \\
\hline III & $11(29.7)$ & $40(35.4)$ & 0.53 \\
\hline IV & $1(2.7)$ & $3(2.7)$ & 0.99 \\
\hline \multicolumn{4}{|l|}{ Priority } \\
\hline Elective & $26(70.3)$ & $96(85.0)$ & 0.05 \\
\hline Urgent & $11(29.7)$ & $17(15.0)$ & 0.05 \\
\hline Emergency & $0(0)$ & $0(0)$ & None \\
\hline \multicolumn{4}{|l|}{$\begin{array}{l}\text { Distal } \\
\text { Anastomosis }\end{array}$} \\
\hline 2 & $9(24.3)$ & $20(17.7)$ & 0.38 \\
\hline 3 & $23(62.2)$ & $83(73.5)$ & 0.19 \\
\hline 4 & $4(10.8)$ & $9(8.0)$ & 0.60 \\
\hline$>4$ & $0(0)$ & $0(0)$ & None \\
\hline
\end{tabular}


distribution were similar. Left ventricular ejection fraction tended to be less often below $50 \%$ in the off-pump group compared to the on-pump group $(16.2 \%$ versus $26.5 \%, p=0.2$ ). In terms of priority there was significantly higher percentage of urgently categorized operations in the off-pump group. There was no emergency operation during the time of the study. In off-pump group number of distal anastmoses with two and four was slightly higher in off-pump surgery. Numbers of three distal anstamoses was considerably less in off-pump sur- gery but did not reach significant value. Logistic EuroSCORE was slightly higher in the off-pump group, with a mean of $3.8 \%$ (range of 0.9 to $21.3 \%$ ) in off-pump versus a mean of $2.9 \%$ (range of $0.9 \%$ to $15.9 \%$ ) in on-pump ( $p=0.19)$.

Continuous and categorical data are summarized in Tables 2(a) (b). Table 2(a) is representing lengths of stays and ventilation times. Table 2(b) depicts conversion rates, mortality, and postoperative complications.

Mean operation time was slightly shorter in the off-

Table 2. (a) Continuous data on lengths of stays and ventilation hours; (b) Categorical data on postoperative parameters comparing off-pump and on-pump group.

(a) Continuous Variables

\begin{tabular}{|c|c|c|c|c|c|c|c|c|}
\hline & & On Pum & & & Off Pum & & & \\
\hline Variable & Mean (SD) & $\begin{array}{l}\text { Trim Mean } \\
\text { (SD) } \\
\text { percentage } \\
\text { trimmed }\end{array}$ & Median (IQR) & Mean (SD) & $\begin{array}{l}\text { Trim Mean } \\
\text { (SD) } \\
\text { Percentage } \\
\text { Trimmed }\end{array}$ & Median (IQR) & $\begin{array}{c}95 \% \\
\text { Confidence } \\
\text { Interval for } \\
\text { Difference in } \\
\text { Means }\end{array}$ & $p$-Value \\
\hline $\begin{array}{l}\text { ICU (mean } \\
\text { days) }\end{array}$ & $2.2(6.8)$ & $1.4(1.0) 6 \%$ & $\begin{array}{c}22 \text { hours }(21-29) \\
0.92 \text { days } \\
(0.89-1.21)\end{array}$ & $2.9(7.7)$ & $\begin{array}{c}1.2(0.6) \\
11 \%\end{array}$ & $\begin{array}{c}23 \text { hours }(21-30) \\
0.96 \text { days } \\
(0.88-1.25)\end{array}$ & $(-0.08,0.48)$ & 0.62 \\
\hline $\begin{array}{l}\text { HDU (mean } \\
\text { days) }\end{array}$ & $1.7(2.8)$ & $1.3(0.9) 4 \%$ & $\begin{array}{l}24 \text { hours }(22-39) \\
1 \text { day }(0.92-1.6)\end{array}$ & $1.4(1.4)$ & $1.3(1.1) 6 \%$ & $\begin{array}{c}24.6 \text { hours }(21-42) \\
1.03 \text { days } \\
(0.88-1.75)\end{array}$ & $(-0.347,0.434)$ & 0.47 \\
\hline $\begin{array}{c}\text { Ward } \\
\text { (mean days) }\end{array}$ & $6.7(9.0)$ & $\begin{array}{c}5.81(5.17) \\
2 \%\end{array}$ & $4.1(3.1-4.1)$ & $4.15(2.3)$ & No outliers & $4(3-5)$ & $(0.44,2.88)$ & 0.01 \\
\hline $\begin{array}{l}\text { Ventilation } \\
\text { (mean hours) }\end{array}$ & $\begin{array}{l}13.30 \\
(25.8)\end{array}$ & $\begin{array}{c}10.5(7.5) \\
4 \%\end{array}$ & $9(6-13)$ & $\begin{array}{c}43.59 \\
(160.2)\end{array}$ & $\begin{array}{c}9.35(5.0) \\
11 \%\end{array}$ & $7.35(6.05-12.5)$ & $(-1.09,3.33)$ & 0.26 \\
\hline $\begin{array}{c}\text { Total Hospital } \\
\text { Stay } \\
\text { (mean days) }\end{array}$ & $10.5(13.8)$ & $\begin{array}{c}8.37(5.5) \\
8 \%\end{array}$ & $6.9(5.7-8.9)$ & $8.47(8.40)$ & $\begin{array}{c}6.88(2.3) \\
12 \%\end{array}$ & $7(5-8)$ & $(0.18,2.8)$ & 0.33 \\
\hline
\end{tabular}

(b) Categorical data

\begin{tabular}{|c|c|c|c|c|c|c|}
\hline \multirow[b]{2}{*}{ Variable } & \multicolumn{2}{|c|}{ On Pump } & \multicolumn{2}{|c|}{ Off Pump } & \multirow[b]{2}{*}{$\begin{array}{l}\text { 95\% Confidence Interval for } \\
\text { Difference in Proportions }\end{array}$} & \multirow[b]{2}{*}{$p$-Value } \\
\hline & $\mathbf{n}$ & Percentage & $\mathbf{n}$ & Percentage & & \\
\hline Atrial Fibrillation & 15 & $13.27 \%$ & 5 & $13.51 \%$ & $(-0.125,0.129)$ & 0.69 \\
\hline Balloon Pump & 1 & $0.88 \%$ & 0 & $0.00 \%$ & $(0.0073,0.0103)$ & 0.56 \\
\hline Reopening for Bleeding & 4 & $3.54 \%$ & 1 & $2.70 \%$ & $(-0.04492,0.06092)$ & 0.64 \\
\hline Acute Renal Failure & 3 & $2.65 \%$ & 1 & $2.70 \%$ & $(-0.0295,0.0605)$ & 0.99 \\
\hline CVA & 0 & $0.0 \%$ & 1 & $2.70 \%$ & $(-0.025,0.079)$ & 0.11 \\
\hline Pneumothorax Requiring Drain & 3 & $2.65 \%$ & 4 & $10.81 \%$ & $(-0.0194,0.1826)$ & 0.04 \\
\hline Pleural Effusion & 3 & $2.65 \%$ & 1 & $2.70 \%$ & $(-0.0613,0.0623)$ & 0.31 \\
\hline In-Hospital Mortality & 0 & $0.00 \%$ & 1 & $2.70 \%$ & $(-0.0029,0.0569)$ & 0.08 \\
\hline Conversion to $\mathrm{CPB}$ & 0 & $0.00 \%$ & 2 & $5.41 \%$ & $(0.0124,0.0958)$ & 0.01 \\
\hline
\end{tabular}


pump group, accounting for three hours and twentyeight minutes mean surgery time in the off-pump group versus three hours and forty-nine minutes in the on-pump group $(p=0.15)$. Mean operation times had no distinctive trend throughout the course of the study period (data not shown). Mean duration of ventilation was non-significantly higher in the off-pump group, with 43.6 hours in the off-pump group versus 13.4 hours in the on-pump group ( $p=0.26$, Figure 1). Mean length of stay in ICU was with 2.9 days slightly higher in the off-pump group versus 2.2 days in the on-pump group. However, the trimmed mean ventilation times showed 9.35 hours in the off-pump group versus 10.6 hours in the on-pump group, representing a modest reduction in ventilation time. Similarly, trimmed mean lengths of ICU stay were 1.2 days in the off-pump group versus 1.4 days in the onpump group ( $p=0.62$ ).

Total hospital stay remained shorter for off-pump patients with a mean length of 8.5 days versus 10.5 days for on-pump patients $(p=0.33)$. Trim mean of hospital length of stay was 6.9 days in the off-pump group versus 8.4 days for the on-pump group ( $p=0.33$ ) (Figure 2).

There was one death in the off-pump group, leading to an in hospital mortality of $2.7 \%$. This patient had under-

Ventilation Hours (Trim Mean) with Standard Error of the Mean

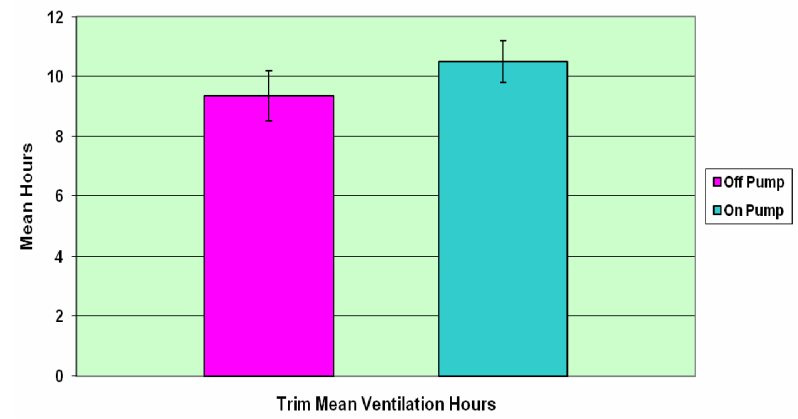

Figure 1. Trim mean of ventilation times in hours for offpump versus on-pump coronary artery bypass grafting.

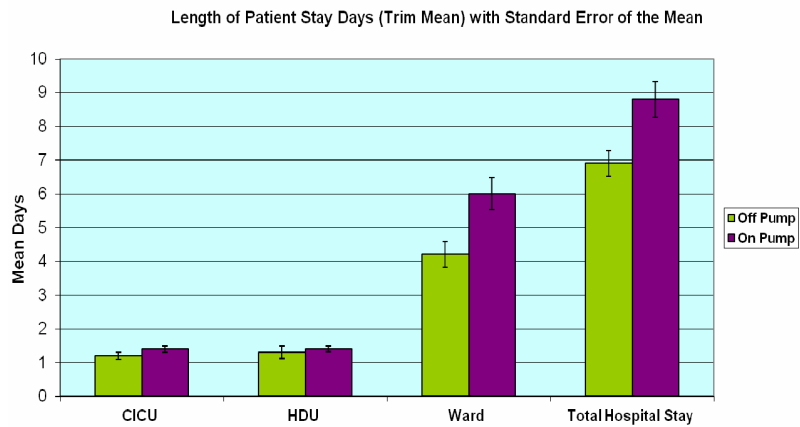

Figure 2. Comparison of off-pump and on-pump group applying Trim Mean for patients' length of stay on intensive care unit (ICU), high dependency unit (HDU), ward and hospital stay. gone emergency conversion from OPCAB to on-pump $\mathrm{CAB}$. In the on-pump group no patient died during hospital stay.

Chest tube drainage was lower for OPCAB (484 milliliter) compared to the on pump surgery (744 milliliter), and this difference was statistically significant $(p=0.04)$. Accordingly, mean discharge hemoglobin $(\mathrm{Hb})$ in the off-pump group was considerably higher than that in the on-pump group (10.6 g/dl versus $10.0 \mathrm{~g} / \mathrm{dl}, p<0.01)$. Blood transfusion was required in $14 \%$ of the off-pump patients and $45 \%$ of the on-pump patients, with a mean of 0.7 and 1.3 red blood cell units, respectively ( $p=$ $0.22)$.

Our data showed almost identical frequency of atrial fibrillation between groups with $13.51 \%$ in off-pump surgery and $13.27 \%$ in CABG surgery $(p=0.97)$. Rates of intra-aortic balloon pump insertion $(0.8 \%$ versus $0.0 \%$, $p=0.56)$ and rates for bleeding requiring re-opening (3.54\% versus $2.70 \%, p=0.64)$ were both slightly higher in off-pump cases. However there were no sternal wound infections in the off-pump group and two in the on-pump group $(1.7 \%, p=0.42)$.

No significant differences were observed for rates of acute renal failure and gastrointestinal complications. Surprisingly the number of pneumothoraces requiring chest drain was significantly higher in the OPCAB group $(10.81 \%$ versus $2.65 \%, p=0.04)$ while pleural effusion rates were similar $(2.70 \%$ versus $2.65 \%, p=0.31)$ (Figure 3).

Cerebro-vascular accident as measure for neurological outcome was recorded during hospital stay. There was one CVA in the off-pump group $(2.7 \%)$ and none in the on-pump group $(p=0.11)$.

\section{Discussion}

We present the results of our early experience in the offpump technique for patients requiring first time, isolated CABG and compared them with a control group of patients receiving conventional on-pump CABG over the same time frame.

Operation time was only slightly shorter in the offpump group and was not showing clear trend towards shorter (or longer) times throughout the reported time frame. With off-pump cardiac surgery there is a potential for shorter operating time due to circumventing cardiopulmonary bypass. In our study taking specialised equipment onto the table, making connections to external sources and ensuring that this equipment worked properly was time consuming. Therefore this effect is possibly a reflection of our early experience. In retrospect, this definitely is a part of the procedure where time efficiencies could be made. Use of a dedicated theatre team in our early experience could also have made this process more efficient. In the long term, we hope to see much 


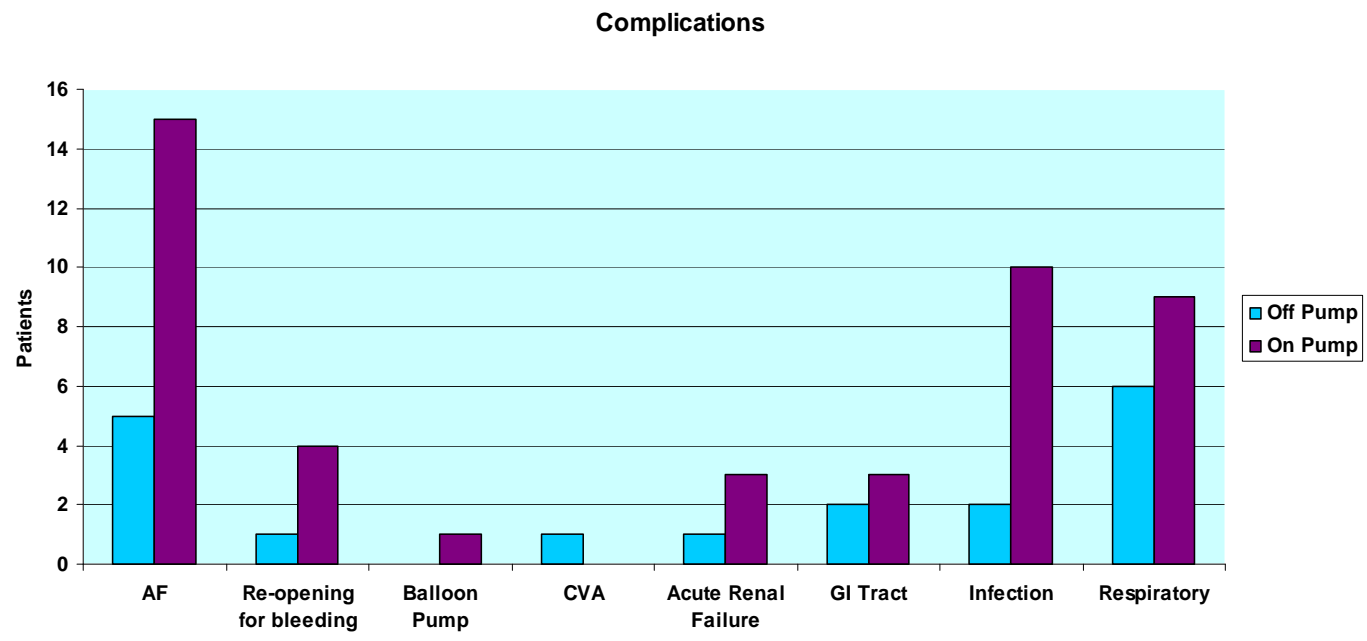

Figure 3. Complications following off-pump and on-pump heart surgery of 150 analysed patients.

reduced operating times.

Reduction in ventilation time, length of ICU stay and hospital length of stay were important and encouraging findings in this analysis.

Theatre protocol for patients undergoing bypass surgery without use of heart-lung machine was modified slightly with regards to Heparin dosages. Close communication between surgeon and anaesthetic team was mandatory. We observed a reduced need for fluids (data not shown). The protocol for $\mathrm{CAB}$ patients of our institution with one day of ICU stay followed by one day in HDU was kept up due to logistic limitations and therefore we believe that there is scope to reduce these times further. It is noteworthy that total hospital stay was significantly shorter in the off-pump group, presumably reflecting much quicker recovery in this group.

Overall mortality and morbidity differed non-significantly in our groups. However, requirement for prolonged mechanical ventilation $>24 \mathrm{~h}$ and the need for IABP were significantly higher in conventional CABG group. The largest randomized controlled trial comparing off-pump and on-pump surgery failed to show a difference in mortality or major complications at one month following surgery in low risk patients [11]. In contrast, a mortality benefit has been observed in large observational studies. The difference is possibly because most RCTs recruit low risk patients whereas the large observational series include patients with significant comorbidities that potentially stand to benefit more from the offpump approach [15]. The one patient who died in the off-pump group had undergone emergency conversion to on-pump CABG, namely urgently instituted CPB after commencement of anastomoses. This is nearly consistent with the $2.2 \%$ off-pump to on-pump surgery conversion rate reported in the Society of Thoracic Surgeons data base study [16]. Emergency conversion to on-pump surgery can have deleterious effects on patient outcomes
[17-19], and is associated with increased perioperative and 3-year mortality, morbidity, and enhanced economic costs (summarized in [18]). Factors leading to all conversions (elective and emergency) are predominantly hemodynamic compromise $(64.1 \%)$, as it was the case in our study, followed by anatomical considerations (problematic target sizes) $(10.5 \%)$, electrophysiological disturbances (9.9\%), graft occlusion/ malfunction (7.0\%), and other or unknown causes (8.4\%) [18]. Strategies to prevent emergency conversion, including elective conversion as another approach with similar outcomes to onpump surgery (ONCAB) or successful OPCAB cases, are being discussed elsewhere [18] and need emphasized. Our patient did not fall in the very early learning period; the surgeon had operated more than twenty patients OPCAB at that time.

In our study we found both, significantly reduced drainage from chest tubes after surgical procedure and higher haemoglobin levels on discharge from hospital in the off-pump group. Higher transfusion requirements contribute to increased morbidity and mortality risk after cardiac surgery. Operative mortality was significantly in patients who were given blood with (or without re-operation than in patients who did not receive blood products (8.7\% blood given and re-operation for bleeding vs. $6.6 \%$ no blood given and re-operation for bleeding, $2.1 \%$ blood given and no re-operation for bleeding vs. 0.099\% no blood used and no re-reoperation). The authors of this propensity matched, prospective cohortinvestigation came to the conclusion that a better attentiveness to surgical techniques for control and decrease bleeding is likely to lower morbidity and mortality [20].

Postoperative atrial fibrillation (POAF) bears the potential for prolonged hospital length of stay and neurological and renal complications [21]. New onset atrial fibrillation after isolated coronary artery bypass surgery independently predicts mortality (hazard ratio, 1.2) [22]. 
In our study POAF was similar in both groups. In contrast to our findings, a recent five-year follow up study demonstrated a significantly higher incidence of AF in off-pump compared to on-pump cases ( $35 \%$ versus $4 \%$ ) [23]. This rate appears to be a lot higher than in both of our study groups. Another randomized study suggested a reduced risk for atrial fibrillation [8].

Although there were no clear differences in our analysis concerning neurological outcome, it is widely suggested that this can be improved in OPCAB and other minimized techniques in surgical revascularization [2426]. Brizzio et al. recently reported a risk of stroke in off-pump compared to on-pump patients as low as $1.0 \%$ versus $2.4 \%(p<0.01)[26]$. The overall stroke rate was $1.7 \%$, which is similar to previous reports. Interestingly, the authors demonstrated, on analysis, that after controlling for certain preoperative risk factors such as history of stroke, age more than 70 years, left ventricular ejection fraction $<35 \%$ ) and the Society of Thoracic Surgeons (STS) mortality risk score, pump status was significantly and independently associated with the mortality outcome after a stroke, with off-pump patients experiencing an $84 \%$ (first time and re-operation), and $80 \%$ (only first time operation), retrospectively, reduced risk of death after stroke [26]. In another study that entailed subgroup analysis of outcomes from the SYNTAX trial, the event rate of stroke one year after surgery tended to be lower with the off-pump no-touch technique when compared with the conventional surgical arm $(0.8 \%$ vs. $2.2 \%$ ) and similar to the percutaneous interventional arm of the SYNTAX trial $(0.6 \%)$ [11]. Furthermore, better cognitive outcomes in off-pump compared to on-pump coronary revascularization have been observed at three months after surgery although this difference disappears after 1 year and remains absent at 5 years (OCTOPUS Study) [9]. Notably, the stroke rate after five years was indistinct with $1.4 \%$ in the off-pump group and $3.6 \%$ in on-pump group $(\mathrm{p}=0.28)$ [9].

The significantly higher rate of pneumothoraces in OPCAB cases was surprising and cannot be explained. The only difference in the two groups is that in OPCAB both pleurae were opened in all cases in contrast to on pump with right pleura opened in only a few cases. Opening both pleurae in off-pump surgery helps to improve hemodynamics and gives optimal positioning of the heart [27]. Cautious intra and postoperative handling as well as more statistical analysis will be necessary to shed light on this issue in the near future.

A significant advantage of off-pump surgery is that it uniquely permits the use of an aortic no-touch technique $[28,29]$ by avoiding aortic manipulation with use of either pedicled or composite arterial grafts, with or without anastomotic devices. The aortic no-touch technique was employed in several of the patients included in our study.
In SYNTAX trial, the off-pump CABG no-touch technique was compared with conventional CABG or PCI. It showed superior results in terms of repeat revascularization $(1.3 \%$ OPCAB No-Touch with total arterial Y-graft, 5.9\% CABG SYNTAX, $13.5 \%$ Taxus SYNTAX), symptomatic graft occlusion $(0.8 \%$ vs. $3.4 \%$ vs. $3.3 \%)$, and also in the percentage of major adverse cardiovascular or cerebrovascular events (5.3\% vs. $12.4 \%$ vs. $17.8 \%$ ) [28].

Optimisation of hemodynamics, stabilization and visualization allow for optimal condition to construct anastomoses. The stabilizers used were up to date and significant learning curves reported in the literature were reported for periods of major technique development, as introduction of deep traction sutures and incorporation of modern stabilizers [5]. We used intraluminal shunts in OPCAB cases and consider these highly advantaging for exposure of intima from both native and conduit vessel, thereby avoiding inadvertent inclusion of the back wall of the native site in the suture line.

The incorporation of OPCAB technique into established surgical practice is done differently throughout the institutions. S. Hoff outlined methods to improve adoption of OPCAB as the following appropriate patient selection, individualized grafting strategy, peer to peer training of the entire team, graded clinical experience (on-pump beating heart, cannulated OPCAB, wet pump, dry pump, and minimally invasive/ advanced OPCAB) [27]. These points were accomplished to satisfactory degree.

Patient selection is generally considered crucial for safe adoption of the off-pump technique. OPCAB-experienced surgeons suggest exclusion of patients with depressed left ventricular function, left main disease, and three-vessel disease in a surgeon's early experience [5]. Yet no indications and contraindications were defined by any authorized institution for training and routine OP$\mathrm{CAB}$ surgery. One patient in the rather early experience was high risk. During the study period the surgeon established an overall rate of OPCAB (24.67\%). It is our feeling that the learning curve can be negotiated with a fairly high initial frequency of ONCAB. However, a reasonable future option of technique incorporation is the formalized training in surgical adoption of the OPCAB technique, prevention and management of emergency conversion as well as leading of a multidisciplinary team [18]. Providing structured training in OPCAB is an effort being made by The American Association for Thoracic Surgery (AATS) and The Society of Thoracic Surgeons (STS). The regarding joint committee (Committee on New Technology Assessment) developed a detailed program, that includes didactic sessions, live animal and cadaver training, observational visits to the institutions of surgeons who are experienced in off-pump surgery and visits by those surgeons (preceptors) to the trainees' home 
institutions [30]. Training to surgical residents we consider paramount in establishing the OPCAB technique in an institution. Eventually additional monitoring using control or cumulative sum (CUSUM) charts may be of great value in the process of introduction of OPCAB and accreditation. These provide a case by case monitoring and, hence, allow for tight quality control, if boundary definitions are put carefully [6].

\section{Limitations}

Our study contains several limitations. Most of all it was a non-randomized retrospective study from which selection bias and diminished comparability result. Although patients were not randomized or matched in any formal manner, we consider that the groups were sufficiently comparable for the purposes of this study. Due to the rough measurement parameter (cerebrovascular accident) neurological outcome was not evaluated in detail, as can be done by cognitive performance tests. Due to the character of the study we did not examine graft patency which is a hotly debated outcome measure in comparison between OPCAB and on-pump CAB.

\section{Conclusion}

The goal of this study was to audit surgical outcomes during the early experience with the off pump technique. We have shown that experienced surgeon could incorporate the off-pump technique safely into surgical practice with relatively little extra training using careful patient selection and up to date materials. The experience will allow us to improve upon these results and bring the benefits of off-pump coronary surgery to the population of patients in need for this option. This article was intended to encourage surgeons yet indistinctive about the technique to start incorporating OPCAB into ones surgical technique. A quick learning curve can be achieved due to careful patient selection, high frequency of OP$\mathrm{CAB}$, use of modern surgical technique and devices, training at teaching centers and a dedicated theatre team.

\section{Acknowledgements}

C. N. thanks Prof. Dr. Ing. Günther Kundt, Institute for Biostatistics and Informatics in Medicine and Ageing Research, University of Rostock, Medical Faculty for his advices.

\section{REFERENCES}

[1] B. J. Hindman, "Emboli, Inflammation, and CNS Impairment: An Overview," The Heart Surgery Forum, Vol. 5, No. 3, 2002, pp. 249-253.

[2] J. R. Pepper, "NICE Guidance for Off-Pump CABG: Keep the Pump Primed," Heart, Vol. 97, No. 21, 2011, pp.
1728-1730. doi:10.1136/heartjnl-2011-300836

[3] B. Bridgewater, R. Kinsman, P. Walton, J. Gummert and A. P. Kappetein, "The 4th European Association for Cardio-Thoracic Surgery Adult Cardiac Surgery Database Report," Interactive Cardiovascular and Thoracic Surgery, Vol. 12, No. 1, 2011, pp. 4-5. doi:10.1510/icvts.2010.251744

[4] V. H. Thourani and R. A. Guyton, "Graft Patency after Off-Pump Coronary Artery Bypass Surgery," Circulation, Vol. 125, 2012, pp. 2806-2808.

[5] H. K. Song, R. J. Petersen, E. Sharoni, R. A. Guyton and J. D. Puskas, "Safe Evolution towards Routine Off-Pump Coronary Artery Bypass: Negotiating the Learning Curve, European Journal Cardio-Thoracic Surgery, Vol. 24, No. 6, 2003, pp. 947-952. doi:10.1016/S1010-7940(03)00616-X

[6] G. J. Murphy, C. A. Rogers, M. Caputo and G. D. Angelini, "Acquiring Proficiency in Off-Pump Surgery: Traversing the Learning Curve, Reproducibility, and Quality Control," The Annals of Thoracic Surgery, Vol. 80, No. 5, 2005, pp. 1965-1970.

doi:10.1016/j.athoracsur.2005.03.037

[7] A. Kourliouros and T. Athanasiou, "Decision Making in Off-Pump Coronary Artery Bypass Surgery: Where Does Conversion Fit in?" Heart, No. 98, No. 18, 2012, pp. 1332-1333.

[8] J. Puskas, D. Cheng, J. Knight, G. Angelini, D. Decannier, A. Diegeler, et al., "Off-Pump versus Conventional Coronary Artery Bypass Grafting: A Meta-Analysis and Consensus Statement from the 2004 ISMICS Consensus Conference," Innovations: Technology \& Techniques in Cardiothoracic \& Vascular Surgery, Vol. 1, No. 1, 2005, pp. 3-27.

[9] D. van Dijk, M. Spoor, R. Hijman, H. M. Nathoe, C. Borst, E. W. Jansen, et al., "Cognitive and Cardiac Outcomes 5 Years after Off-Pump vs On-Pump Coronary Artery Bypass Graft Surgery," JAMA: The Journal of the American Medical Association, Vol. 297, No. 7, 2007, pp. 701-708. doi:10.1001/jama.297.7.701

[10] B. Hattler, J. C. Messenger, A. L. Shroyer, J. F. Collins, S.J. Haugen, J.A. Garcia, et al., "Off-Pump Coronary Artery Bypass Surgery Is Associated with Worse Arterial and Saphenous Vein Graft Patency and Less Effective Revascularization: Results from the Veterans Affairs Randomized on/off Bypass (ROOBY) Trial," Circulation, Vol. 125, No. 23, 2012, pp. 2827-2835.

[11] A. L. Shroyer, F. L. Grover, B. Hattler, J. F. Collins, G. O. McDonald, E. Kozora, et al., "On-Pump versus Off-Pump Coronary-Artery Bypass Surgery," New England Journal of Medicine, Vol. 361, 2009, pp. 1827-1837. doi:10.1056/NEJMo a0902905

[12] A. S. Ramadan, C. Stefanidis, W. N'Gatchou, B. El Oumeiri, J. L. Jansens, J. M. De Smet, et al., "Five Years Follow-Up after Y-Graft Arterial Revascularization: OnPump versus Off-Pump; Prospective Clinical Trial," Interactive Cardiovascular Thoracic Surgery, Vol. 10, No. 3, pp. 423-427. doi:10.1510/icvts.2009.206458

[13] G. D. Angelini, L. Culliford, D. K. Smith, M. C. Hamilton, G. J. Murphy, R. Ascione, et al., "Effects of On- and 
Off-Pump Coronary Artery Surgery on Graft Patency, Survival, and Health-Related Quality of Life: Long-Term Follow-Up of 2 Randomized Controlled Trials," The Journal of Thoracic and Cardiovascular Surgery, Vol. 137, No. 2, 2009, pp. 295-303. doi:10.1016/j.jtcvs.2008.09.046

[14] Y. Abu-Omar and D. P. Taggart, "The Present Status of Off-Pump Coronary Artery Bypass Grafting," European Journal of Cardio-Thoracic Surgery, Vol. 36, No. 2, 2009, pp. 312-321. doi:10.1016/j.ejcts.2009.03.025

[15] D. N. Wijeysundera, W. S. Beattie, G. Djaiani, V. Rao, M. A. Borger, K. Karkouti, et al., "Off-Pump Coronary Artery Surgery for Reducing Mortality and Morbidity: Meta-Analysis of Randomized and Observational Studies," Journal of the American College of Cardiology, Vol. 46, No. 5, 2005, pp. 872-882. doi:10.1016/j.jacc.2005.05.064

[16] J. D. Puskas, F. H. Edwards, P. A. Pappas, S. O'Brien, E. D. Peterson, P. Kilgo, et al., "Off-Pump Techniques Benefit Men and Women and Narrow the Disparity in Mortality after Coronary Bypass Grafting," The Annals of Thoracic Surgery, Vol. 84, No. 5, 2007, pp. 1447-1456.

[17] N. C. Patel, N. U. Patel, D. F. Loulmet, J. C. McCabe and V. A. Subramanian, "Emergency Conversion to Cardiopulmonary Bypass during Attempted Off-Pump Revascularization Results in Increased Morbidity and Mortality," The Journal of Thoracic and Cardiovascular Surgery, Vol. 128, No. 5, 2004, pp. 655-661. doi:10.1016/j.jtcvs.2004.04.043

[18] D. Mukherjee, K. Ahmed, K. Baig, V. M. Patel, A. Darzi and T. Athanasiou, "Conversion and Safety in Off-Pump Coronary Artery Bypass: A System Failure That Needs Re-Emphasis," The Annals of Thoracic Surgery, Vol. 91, No. 2, 2011, pp. 630-639. doi:10.1016/j.athoracsur.2010.10.031

[19] A. Hovakimyan, V. Manukyan, S. Ghazaryan, M. Saghatelyan, L. Abrahamyan and H. Hovaguimian, "Predictors of Emergency Conversion to On-Pump during OffPump Coronary Surgery," Asian Cardiovascular \& Thoracic Annals, Vol. 16, No. 3, 2008, pp. 226-230.

[20] A. Vivacqua, C. G. Koch, A. M. Yousuf, E. R. Nowicki, P. L. Houghtaling, E. H. Blackstone, et al., "Morbidity of Bleeding after Cardiac Surgery: Is It Blood Transfusion, Reoperation for Bleeding, or Both?" The Annals of Thoracic Surgery, Vol. 91, No. 6, 2011, pp. 1780-1790. doi:10.1016/j.athoracsur.2011.03.105

[21] S. G. Nair, "Atrial Fibrillation after Cardiac Surgery," Annals of Cardiac Anaesthesia, Vol. 13, No. 3, pp. 196205. doi:10.4103/ 0971-9784.69047

[22] M. F. El-Chami, P. Kilgo, V. Thourani, O. M. Lattouf, D. B. Delurgio, R. A. Guyton, et al., "New-Onset Atrial Fib- rillation Predicts Long-Term Mortality after Coronary Artery Bypass Graft," Journal of the American College of Cardiology, Vol. 55, No. 13, 2010, pp. 1370-1376. doi:10.1016/i.jacc.2009.10.058

[23] W. Hueb, N. H. Lopes, A. C. Pereira, A. C. Hueb, P. R. Soares, D. Favarato, et al., "Five-Year Follow-Up of a Randomized Comparison between Off-Pump and OnPump Stable Multivessel Coronary Artery Bypass Grafting. The MASS III Trial," Circulation, Vol. 122, pp. S48S52. doi:10.1161/CIRCULATIONAHA.109.924258

[24] A. Sedrakyan, A. W. Wu, A. Parashar, E. B. Bass and T. Treasure, "Off-Pump Surgery Is Associated with Reduced Occurrence of Stroke and Other Morbidity as Compared with Traditional Coronary Artery Bypass Grafting: A Meta-Analysis of Systematically Reviewed Trials," Stroke, Vol. 37, No. 11, 2006, pp. 2759-2769. doi:10.1161/01.STR. 0000 245081.52877.f2

[25] J. D. Puskas, W. H. Williams, P. G. Duke, J. R. Staples, K. E. Glas, J. J. Marshall, et al., "Off-Pump Coronary Artery Bypass Grafting Provides Complete Revascularization with Reduced Myocardial Injury, Transfusion Requirements, and Length of Stay: A Prospective Randomized Comparison of Two Hundred Unselected Patients Undergoing Off-Pump versus Conventional Coronary Artery Bypass Grafting," The Journal of Thoracic and Cardiovascular Surgery, Vol. 125, No. 4, 2003, pp. 797-808. doi: $10.1067 / \mathrm{mtc} .2003 .324$

[26] M. E. Brizzio, A. Zapolanski, R. E. Shaw, J. S. Sperling and B. P. Mindich, "Stroke-Related Mortality in Coronary Surgery Is Reduced by the Off-Pump Approach," The Annals of Thoracic Surgery, Vol. 89, No. 1, pp. 1923. doi:10.1016/j.athoracsur.2009.07.076

[27] S. J. Hoff, "Off-Pump Coronary Artery Bypass: Techniques, Pitfalls, and Results," Seminars in Thoracic and Cardiovascular Surgery, Vol. 21, No. 3, 2009, pp. 213223. doi:10.1053/j.semtcvs.2009.09.002

[28] W.B. Halbersma, S.C. Arrigoni, G. Mecozzi, J.G. Grandjean, A.P. Kappetein, J. van der Palen, et al., "Four-Year Outcome of OPCAB No-Touch with Total Arterial YGraft: Making the Best Treatment a Daily Practice," The Annals of Thoracic Surgery, Vol. 88, No. 3, 2009, pp. 796-801. doi:10.1016/j.athoracsur.2009.04.104

[29] M.Y. Emmert, B. Seifert, M. Wilhelm, J. Grunenfelder, V. Falk and S. P. Salzberg, "Aortic No-Touch Technique Makes the Difference in Off-Pump Coronary Artery Bypass Grafting," The Journal of Thoracic and Cardiovascular Surgery, Vol. 142, No. 6, 2011, pp. 1499-1506.

[30] B. W. Lytle, "Evolving Technology: Recognition and Opportunity," The Annals of Thoracic Surgery, Vol. 71, No. 5, 2001, p. 1409. doi:10.1016/S0003-4975(01)02538-3 